\title{
Structure and some magnetic properties of $\left(\mathrm{BiFeO}_{3}\right)_{x}-\left(\mathrm{BaTiO}_{3}\right)_{1-x}$ solid solutions prepared by solid-state sintering
}

\author{
Karol Kowal, \\ Maciej Kowalczyk, \\ Dionizy Czekaj, \\ Elżbieta Jartych
}

\begin{abstract}
This paper presents the results of the study on structure and magnetic properties of the perovskite-type $\left(\mathrm{BiFeO}_{3}\right)_{x}-\left(\mathrm{BaTiO}_{3}\right)_{1-x}$ solid solutions. The samples differing in the chemical composition $(x=0.9,0.8$, and 0.7$)$ were produced according to the conventional solid-state sintering method from the mixture of powders. Moreover, three different variants of the fabrication process differing in the temperatures and soaking time were applied. The results of X-ray diffraction (XRD), Mössbauer spectroscopy (MS), and vibrating sample magnetometry (VSM) were collected and compared for the set of the investigated materials. The structural transformation from rhombohedral to cubic symmetry was observed for the samples with $x=0.7$. With increasing of $\mathrm{BaTiO}_{3}$ concentration Mössbauer spectra become broadened reflecting various configurations of atoms around ${ }^{57} \mathrm{Fe}$ probes. Moreover, gradual decreasing of the average hyperfine magnetic field and macroscopic magnetization were observed with $x$ decreasing.
\end{abstract}

Key words: hyperfine interactions • magnetization • Mössbauer spectroscopy $\bullet$ multiferroics

\author{
K. Kowal ${ }^{凶}$ \\ Institute of Electronics and Information Technology, \\ Lublin University of Technology, \\ 38A Nadbystrzycka Str., 20-618 Lublin, Poland \\ and Nuclear Energy Division, \\ National Centre for Nuclear Research, \\ 7 A. Sołtana Str., 05-400 Otwock/Świerk, Poland, \\ Tel.: +48 22273 1307, Fax: +48 22779 3481, \\ E-mail: k.kowal@ncbj.gov.pl \\ M. Kowalczyk \\ Faculty of Materials Science and Engineering, \\ Warsaw University of Technology, \\ 141 Wołoska Str., 02-507 Warsaw, Poland

\section{Czekaj} \\ Department of Materials Science, \\ University of Silesia, \\ 2 Śnieżna Str., 41-200 Sosnowiec, Poland \\ E. Jartych \\ Institute of Electronics and Information Technology, \\ Lublin University of Technology, \\ 38A Nadbystrzycka Str., 20-618 Lublin, Poland
}

Received: 18 June 2014

Accepted: 2 Novemver 2014

\section{Introduction}

The rapidly growing interest in $\left(\mathrm{BiFeO}_{3}\right)_{x}-\left(\mathrm{BaTiO}_{3}\right)_{1-x}$ solid solutions is caused by their multiferroic properties, that is, coexistence of both the electric and magnetic ordering. It creates possibility for many innovative applications, for example, in steering the magnetic memory by electric field and vice versa. In $\left(\mathrm{BiFeO}_{3}\right)_{x}-\left(\mathrm{BaTiO}_{3}\right)_{1-x}$ solid solutions the room-temperature magnetoelectric coupling exhibit significant magnitude in the narrow composition window $(x=0.71-0.80)$ where the crystalline structure is rhombohedral. As reported in [1], the maximum value of magnetoelectric voltage coefficient $\alpha_{\mathrm{ME}}=$ $0.87 \mathrm{mV} \cdot \mathrm{cm}^{-1} \cdot \mathrm{Oe}^{-1}$ was obtained for $0.725 \mathrm{BiFeO}_{3}$ $-0.275 \mathrm{BaTiO}_{3}$ solid solution what provides a possibility of developing electrically or magnetically tunable thin-film devices. Our latest investigations proved that initial electric poling of the samples allowed to enhancing magnetoelectric effect up to $\alpha_{\mathrm{ME}}=$ $1.53 \mathrm{mV} \cdot \mathrm{cm}^{-1} \cdot \mathrm{Oe}^{-1}$ for $0.7 \mathrm{BiFeO}_{3}-0.3 \mathrm{BaTiO}_{3}$ sintered at $1153 \mathrm{~K} \mathrm{[2].}$

In spite of an intense effort directed at creating and probing $\mathrm{BiFeO}_{3}$-based solid solutions, a fundamental understanding of structure-property correlations in these systems is still lacking. Many parameters, like crystallite sizes, morphology, purity, and precise chemical composition may have the influence on the ferroic ordering and the associated magnetic response. The aim of the present work 
is a deeper insight in the structure and magnetic behavior of the investigated materials as well as the hyperfine interactions of ${ }^{57} \mathrm{Fe}$ nuclei located in $\left(\mathrm{BiFeO}_{3}\right)_{x}-\left(\mathrm{BaTiO}_{3}\right)_{1-x}$ solid solutions. The materials were prepared by the conventional solid-state sintering method under various technological conditions. X-ray diffraction (XRD), ${ }^{57} \mathrm{Fe}$ Mössbauer spectroscopy (MS), and vibrating sample magnetometry (VSM) were applied as complementary methods to investigate the materials.

\section{Experimental details}

Three different variants of conventional solid-state sintering method differing in the applied temperatures and soaking time have been used to prepare three series of $\left(\mathrm{BiFeO}_{3}\right)_{x}-\left(\mathrm{BaTiO}_{3}\right)_{1-x}$ samples of various chemical compositions, that is, $x=0.7,0.8$, 0.9 . The investigated materials were obtained from precursor oxides $\mathrm{Bi}_{2} \mathrm{O}_{3}, \mathrm{Fe}_{2} \mathrm{O}_{3}, \mathrm{TiO}_{2}$, and barium carbonate $\left(\mathrm{BaCO}_{3}\right)$ according to the following formula:

$$
\begin{aligned}
\left(\mathrm{Bi}_{2} \mathrm{O}_{3}\right)_{x / 2} & +\left(\mathrm{Fe}_{2} \mathrm{O}_{3}\right)_{x / 2}+\left(\mathrm{BaCO}_{3}\right)_{1-x} \\
+\left(\mathrm{TiO}_{2}\right)_{1-x} \rightarrow & \left(\mathrm{BiFeO}_{3}\right)_{x}-\left(\mathrm{BaTiO}_{3}\right)_{1-x} \\
& +\left(\mathrm{CO}_{2}\right)_{1-x}
\end{aligned}
$$

The solid-state sintering method used in this experiment included double synthesis, final sintering, and annealing in the air. The three-stage process of thermal treatment was applied to obtain better phase formation. After the first heat-treatment (synthesis I) the material was ground into powder and homogenized. Then the second heat-treatment process (synthesis II) was performed and the resultant material was powdered and homogenized once again. Finally, the obtained ceramics was sintered. Technological parameters of the samples fabrication are presented in Table 1, the details of that process have been described elsewhere in $[3,4]$.

X-ray diffraction analysis was performed in order to examine the crystalline structure of as-prepared solid solutions. The measurements were carried out at room temperature by usage of Philips PW3710 diffractometer with $\mathrm{CoK} \alpha$ radiation, operating in the Bragg-Brentano geometry in the range of $2 \theta$ angle from $10^{\circ}$ to $90^{\circ}$ with a step of $2 \theta$ equal to $0.008^{\circ}$. The obtained XRD patterns were analyzed with the help of X'Pert High Score Plus computer program.

The hyperfine interactions of ${ }^{57} \mathrm{Fe}$ located in $\left(\mathrm{BiFeO}_{3}\right)_{x}-\left(\mathrm{BaTiO}_{3}\right)_{1-x}$ solid solutions were investigated by application of the Mössbauer spectroscopy as a method complementary to XRD. The Mössbauer spectra were collected at room temperature in transmission geometry using a source of ${ }^{57} \mathrm{Co}$ in a chromium matrix. The investigated solid solutions in tablets were crushed and powdered to prepare ab- sorbers. The spectrometer was calibrated before each measurement using a $25-\mu \mathrm{m}$-thick metallic iron foil.

Magnetic measurements at room temperature were performed on Vibrating Sample Magnetometer device produced by Lake Shore (model 7440). Magnetic field was produced by current in the electromagnetic coils and its value varied in the range of $-1600 \div 1600 \mathrm{kA} / \mathrm{m}(-20 \div 20 \mathrm{kOe})$. The field was changed continuously in the regime: $0-\mathrm{H}_{\max }-$ $\mathrm{H}_{\min }-\mathrm{H}_{\max }-0$. Magnetic response of material was collected with an accuracy of $5 \times 10^{-6} \mu_{\mathrm{B}} / \mathrm{f}$.u. (Bohr magneton per formula unit). Mass of the sample was in the range of ten milligrams measured on precise balance with an accuracy of $0.1 \mathrm{mg}$.

\section{Results and discussion}

The crystalline structure of the $\left(\mathrm{BiFeO}_{3}\right)_{x}-\left(\mathrm{BaTiO}_{3}\right)_{1-x}$ solid solutions was examined by powder XRD measurements. In Fig. 1, XRD patterns are collected for each composition in dependence on the sintering temperature (i.e. for each variant of technological process). For $0.9 \mathrm{BiFeO}_{3}-0.1 \mathrm{BaTiO}_{3}$ (Fig. 1a) and $0.8 \mathrm{BiFeO}_{3}-0.2 \mathrm{BaTiO}_{3}$ (Fig. 1b) solid solutions all diffraction lines can be indexed to the rhombohedral structure of $\mathrm{BiFeO}_{3}$ (space group $R 3 c$, card number ICSD 01-071-2494). In the case of $0.9 \mathrm{BiFeO}_{3}-$ $-0.1 \mathrm{BaTiO}_{3}$ solid solution sintered at $1103 \mathrm{~K}$ small amount (about $6 \mathrm{wt} \%$ ) of impurity by $\mathrm{Bi}_{2} \mathrm{Fe}_{4} \mathrm{O}_{9}$ compound (space group Pbam, card number JCPDS 00$-025-0090)$ was detected. For $0.7 \mathrm{BiFeO}_{3}-0.3 \mathrm{BaTiO}_{3}$ diffraction lines can be indexed to the cubic lattice of $\mathrm{BaTiO}_{3}$ (space group $\mathrm{Pm} 3 \mathrm{~m}$, card number ICSD 01-074-1961). However, the asymmetry of the lines corresponding to $2 \theta$ about 67 degrees indicates coexistence of a small amount of the rhombohedral phase as well (Fig. 1d). The observed structural transformation from rhombohedral to cubic for $x=$ 0.7 has been reported many times in the literature $[1,5-7]$.

Room-temperature Mössbauer spectra for the investigated solid solutions are presented in Fig. 2. For each composition the spectra are six-line patterns and the doublet component with higher or smaller amplitude may be observed in the central part of the spectrum. The hyperfine interaction parameters of the quadrupolar component for $0.9 \mathrm{BiFeO}_{3}-$ $-0.1 \mathrm{BaTiO}_{3}$ and $0.8 \mathrm{BiFeO}_{3}-0.2 \mathrm{BaTiO}_{3}$ solid solutions are as follows: the isomer shift $\delta=0.26 \mathrm{~mm} \cdot \mathrm{s}^{-1}$ and the quadrupole splitting $\Delta=0.52 \div 0.74 \mathrm{~mm} \cdot \mathrm{s}^{-1}$ (in dependence on the composition and sintering temperature). In these two cases the doublet may be attributed to the paramagnetic $\mathrm{Bi}_{2} \mathrm{Fe}_{4} \mathrm{O}_{9}$ impurity phase, the obtained hyperfine interactions parameters are in good agreement with the literature data [8]. In the case of $0.7 \mathrm{BiFeO}_{3}-0.3 \mathrm{BaTiO}_{3}$ solid solu-

Table 1. Technological parameters of the synthesis of $\left(\mathrm{BiFeO}_{3}\right)_{x^{-}}\left(\mathrm{BaTiO}_{3}\right)_{1-x}$ solid solutions [3]

\begin{tabular}{lllll}
\hline \multicolumn{1}{c}{ Methods } & Synthesis I & Synthesis II & Sintering & Annealing \\
\hline Variant I & $1023 \mathrm{~K} / 20 \mathrm{~h}$ & $1023 \mathrm{~K} / 20 \mathrm{~h}$ & $1053 \mathrm{~K} / 40 \mathrm{~h}$ & $823 \mathrm{~K} / 10 \mathrm{~h}$ \\
Variant II & $1073 \mathrm{~K} / 10 \mathrm{~h}$ & $1073 \mathrm{~K} / 10 \mathrm{~h}$ & $1103 \mathrm{~K} / 20 \mathrm{~h}$ & $823 \mathrm{~K} / 10 \mathrm{~h}$ \\
Variant III & $1123 \mathrm{~K} / 2 \mathrm{~h}$ & $1123 \mathrm{~K} / 2 \mathrm{~h}$ & $1153 \mathrm{~K} / 4 \mathrm{~h}$ & $823 \mathrm{~K} / 10 \mathrm{~h}$ \\
\hline
\end{tabular}



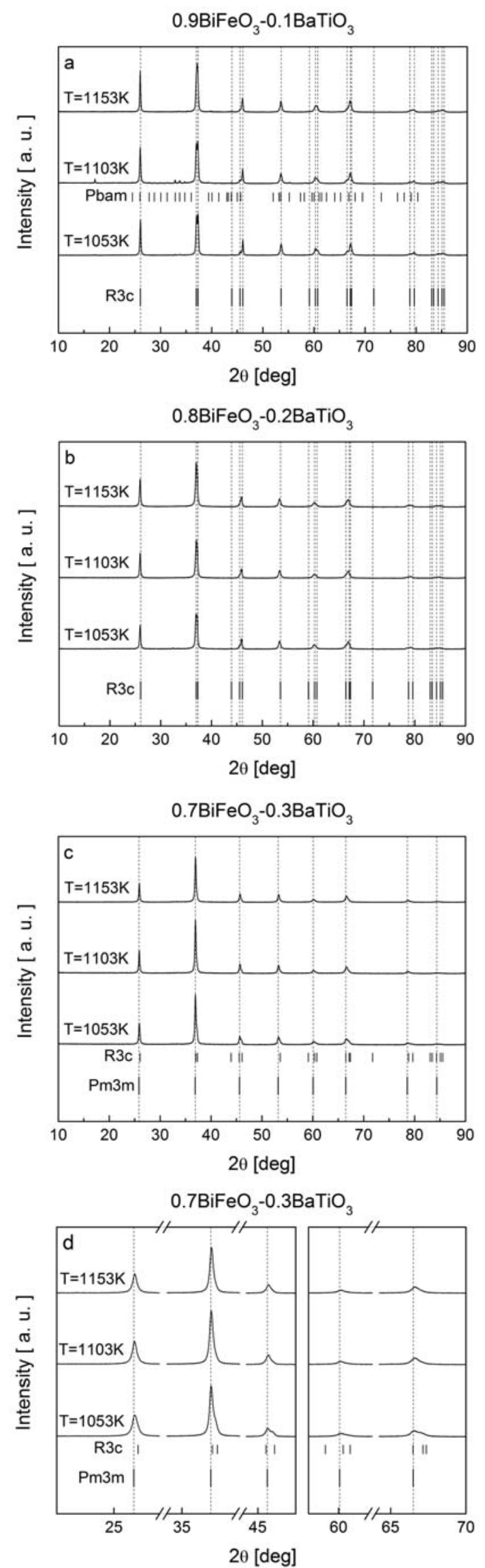

Fig. 1. X-ray diffraction patterns of $\left(\mathrm{BiFeO}_{3}\right)_{x}-\left(\mathrm{BaTiO}_{3}\right)_{1-x}$ solid solutions in dependence on sintering temperature; (a) $x=0.9$, (b) $x=0.8$, (c) $x=0.7$, (d) $x=0.7-$ expanded view of XRD for selected values of $2 \theta$.
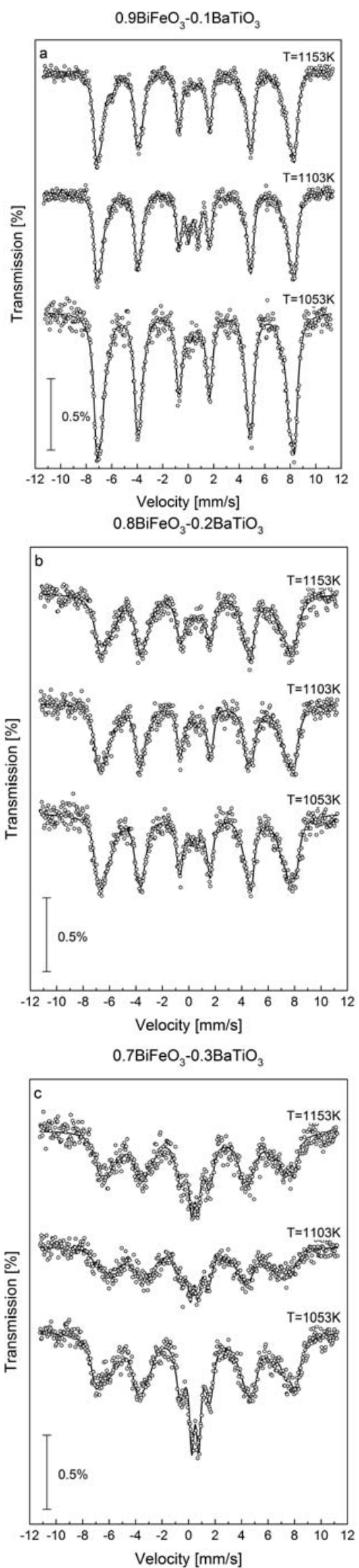

Fig. 2. Room-temperature Mössbauer spectra of $\left(\mathrm{BiFeO}_{3}\right)_{x}-\left(\mathrm{BaTiO}_{3}\right)_{1-x}$ solid solutions in dependence on sintering temperature; (a) $x=0.9$, (b) $x=0.8$, (c) $x=0.7$. 
tion, the doublet with parameters $\delta=0.35 \mathrm{~mm} \cdot \mathrm{s}^{-1}$ and $\Delta=0.52 \mathrm{~mm} \cdot \mathrm{s}^{-1}$ may be connected with cubic phase. The obtained parameters are similar to those for $0.5 \mathrm{BiFeO}_{3}-0.5 \mathrm{BaTiO}_{3}$ solid solution prepared by molten salt method (i.e. $\delta=0.31 \mathrm{~mm} \cdot \mathrm{s}^{-1}$ and $\Delta=$ $\left.0.50 \mathrm{~mm} \cdot \mathrm{s}^{-1}\right)$ [7].

As the content of $\mathrm{BaTiO}_{3}$ increases, the spectra become broadened because of random distribution of $\mathrm{Fe}^{3+}$ ions which substitute $\mathrm{Ti}^{4+}$ ions within the structure of $\left(\mathrm{BiFeO}_{3}\right)_{x}-\left(\mathrm{BaTiO}_{3}\right)_{1-x}$ solid solutions. The best numerical fitting of the spectra was obtained with applying a probability distribution of hyperfine magnetic field (HMF) at ${ }^{57} \mathrm{Fe}$ with the fixed quadrupole doublet component. The HMF probability distributions for the studied solid solutions are presented in Fig. 3. The values of hyperfine magnetic fields for $0.9 \mathrm{BiFeO}_{3}-0.1 \mathrm{BaTiO}_{3}$ solid solution are in the range of 38-53 $\mathrm{T}$ and the most
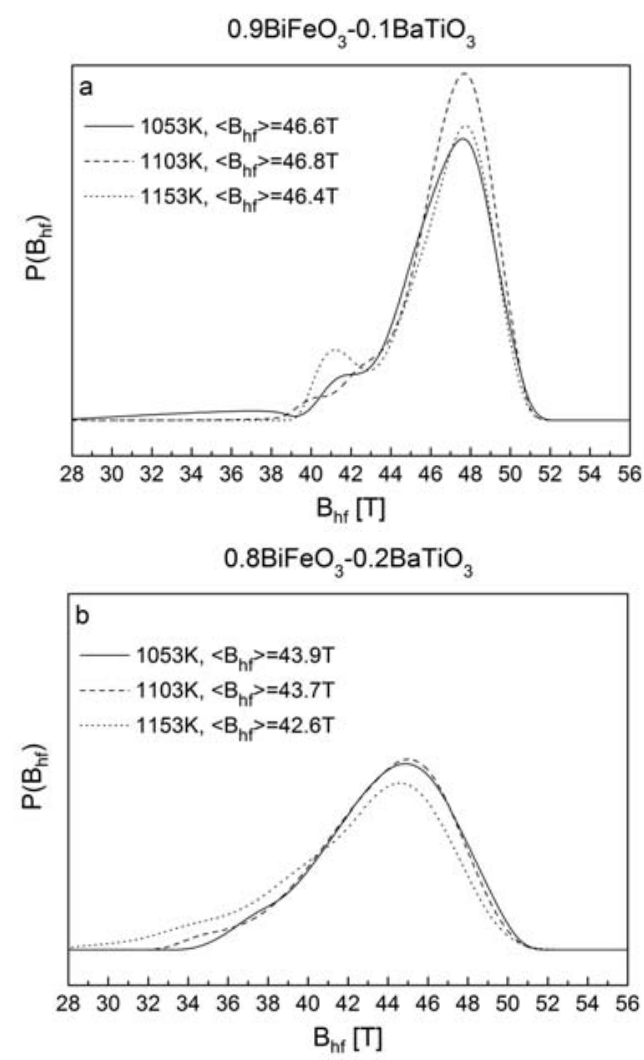

$0.7 \mathrm{BiFeO}_{3}-0.3 \mathrm{BaTiO}_{3}$

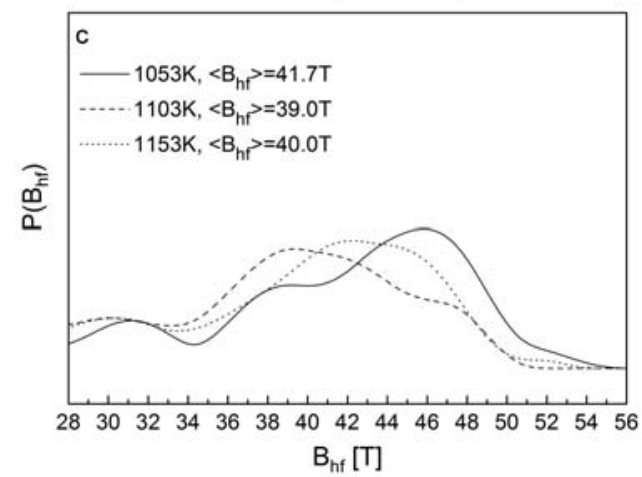

Fig. 3. Probability distribution for hyperfine magnetic field at ${ }^{57} \mathrm{Fe}$ nuclei located in $\left(\mathrm{BiFeO}_{3}\right)_{x}-\left(\mathrm{BaTiO}_{3}\right)_{1-x}$ solid solutions in dependence on sintering temperature; (a) $x=0.9$, (b) $x=0.8$, (c) $x=0.7$. probable field is about $48.0 \mathrm{~T}$ independently on the sintering temperature. In the case of $0.8 \mathrm{BiFeO}_{3^{-}}$ $-0.2 \mathrm{BaTiO}_{3}$ and $0.7 \mathrm{BiFeO}_{3}-0.3 \mathrm{BaTiO}_{3}$ solid solution fields with lower values appear in the distributions (27-33 T). The most probable HMF is about $44.7 \mathrm{~T}$ for $x=0.8$ for all the sintering temperatures. In the case of $x=0.7$, the largest discrepancies in the HMF distributions may be observed. The average values of the hyperfine magnetic field determined from the distributions are presented in Fig. 3. Independently on the sintering temperature the average HMF value decreases with increase of $\mathrm{BaTiO}_{3}$ concentration. Our results are in good agreement with the data reported for the $\left(\mathrm{BiFeO}_{3}\right)_{x}-\left(\mathrm{BaTiO}_{3}\right)_{1-x}$ solid solutions prepared by a molten salt method (i.e. $\left\langle B_{\mathrm{hf}}\right\rangle$ $=47.7 \mathrm{~T}$ for $x=0.9,<B_{\mathrm{hf}}>=43.9 \mathrm{~T}$ for $x=0.8$ and $\left\langle B_{\mathrm{hf}}>=40.6 \mathrm{~T}\right.$ for $x=0.7$ ) [7].

On the basis of XRD and MS results it may be stated that the structural transformation of $\left(\mathrm{BiFeO}_{3}\right)_{x}-\left(\mathrm{BaTiO}_{3}\right)_{1-x}$ solid solutions is accompanied by the change of magnetic order. Pure $\mathrm{BiFeO}_{3}$ compound is both antiferromagnetic and ferroelectric at room temperature. Adding of $\mathrm{BaTiO}_{3}$ destroy the spiral magnetic structure of the $\mathrm{BiFeO}_{3}$ leading to the release of the inherent magnetization of this canted antiferromagnet. In a consequence, the multiferroic properties of $\left(\mathrm{BiFeO}_{3}\right)_{x}-\left(\mathrm{BaTiO}_{3}\right)_{1-x}$ solid solutions are improved and the linear magnetoelectric effect may be observed [9]. To investigate the macroscopic magnetic properties of $\left(\mathrm{BiFeO}_{3}\right)_{x}-\left(\mathrm{BaTiO}_{3}\right)_{1-x}$ solid solutions room-temperature magnetic measurements were performed using VSM. The obtained hysteresis loops are shown in Fig. 4 for the samples sintered at $1103 \mathrm{~K}$. The largest magnetic response, that is, maximum magnetic moment $\mu_{\max }$, was registered at the applied magnetic field of $1600 \mathrm{kA} / \mathrm{m}$. It may be observed that increasing the content of $\mathrm{BaTiO}_{3}$ caused a decreasing of $\mu_{\max }$ from about $7.9 \times 10^{-2} \mu_{\mathrm{B}} /$ f.u. (equivalent of saturation magnetization $M_{s} \sim 1.46 \mathrm{emu} / \mathrm{g}$ ) for $0.9 \mathrm{BiFeO}_{3}-0.1 \mathrm{BaTiO}_{3}$ solid solution by $7.1 \times 10^{-2} \mu_{\mathrm{B}} /$ f.u. $\left(M_{\mathrm{s}} \sim 1.34 \mathrm{emu} / \mathrm{g}\right)$ for $0.8 \mathrm{BiFeO}_{3}-0.2 \mathrm{BaTiO}_{3}$ down to $5.4 \times 10^{-2} \mu_{\mathrm{B}} /$ f.u. $\left(M_{s} \sim 1.04 \mathrm{emu} / \mathrm{g}\right)$ for $0.7 \mathrm{BiFeO}_{3}-0.3 \mathrm{BaTiO}_{3}$, respectively. The obtained values are slightly different than those reported for nanostructural $\left(\mathrm{BiFeO}_{3}\right)_{x}-\left(\mathrm{BaTiO}_{3}\right)_{1-x}$ solid solutions $\left(M_{s} \sim\right.$ $1.04 \mathrm{emu} / \mathrm{g}$ for $x=0.9, M_{s} \sim 1.88 \mathrm{emu} / \mathrm{g}$ for $x=$ 0.8 and $M_{s} \sim 1.61 \mathrm{emu} / \mathrm{g}$ for $x=0.7$ ) [7]; however,

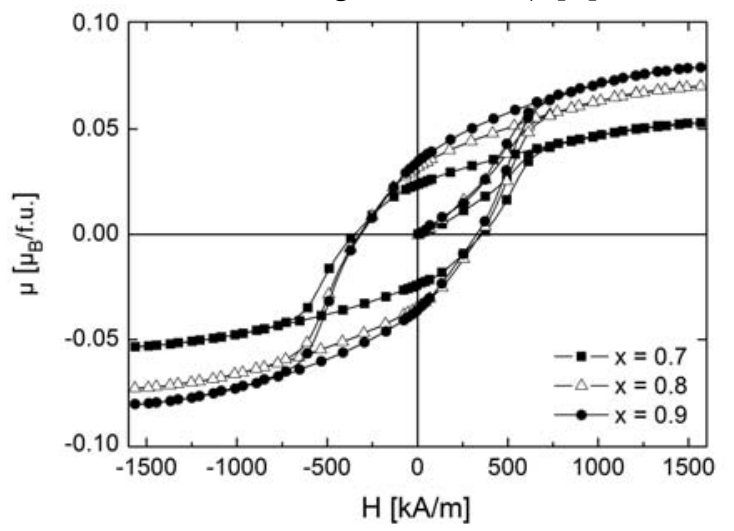

Fig. 4. Room-temperature hysteresis loops of $\left(\mathrm{BiFeO}_{3}\right)_{x}-\left(\mathrm{BaTiO}_{3}\right)_{1-x}$ solid solutions sintered at $1103 \mathrm{~K}$. 
these discrepancies may be due to the preparation method. It may be added that the remnant magnetization $\sim 0.5 \mathrm{emu} / \mathrm{g}$ corresponding to $\mu \sim 2.7 \times 10^{-2}$ $\mu_{\mathrm{B}} /$ f.u. measured for our solid solutions is almost an order of magnitude higher than that from literature $(\sim 0.08 \mathrm{emu} / \mathrm{g})[10]$. Moreover, coercivity $400 \mathrm{kA} / \mathrm{m}$ (5 kOe) is significantly higher than that measured for typical $\left(\mathrm{BiFeO}_{3}\right)_{x}-\left(\mathrm{BaTiO}_{3}\right)_{1-x}$ solid solutions (1.3-3.4 kOe) [7].

\section{Conclusions}

XRD, MS, and VSM techniques indicated the relationship between the content of $\mathrm{BiFeO}_{3}$ and the magnetic properties of the investigated $\left(\mathrm{BiFeO}_{3}\right)_{x}-\left(\mathrm{BaTiO}_{3}\right)_{1-x}$ solid solutions. Decrease of $\mathrm{BiFeO}_{3}$ concentration causes structural transformation from rhombohedral to cubic symmetry. The decreasing of the average hyperfine magnetic field as well as macroscopic magnetization was observed with $x$ decreasing. This reflects the weakening of the inherent strength of the magnetic interactions and increasing disorder in magnetic moments arrangement. The structure and magnetic properties of the investigated materials for a given $x$ value are very similar despite the different sintering conditions. Thus, the third variant of the synthesis process involving the temperature rising of 100 degrees seems to be the most efficient one due to the significantly shorter time of the samples preparation.

\section{References}

1. Yang, S. -Ch., Kumar, A., Petkov, V., \& Priya, S. (2013). Room-temperature magnetoelectric coupling in single-phase $\mathrm{BaTiO}_{3}-\mathrm{BiFeO}_{3}$ system. J. Appl. Phys., 113, 144101-1-5. DOI: 10.1063/1.4799591.

2. Jartych, E., Pikula, T., Kowal, K., Lisińska-Czekaj, A., \& Czekaj, D. (2014). Mössbauer spectroscopy and magnetoelectric effect studies of multiferroic ceramics based on $\mathrm{BiFeO}_{3}$. Key Eng. Mater., 602/603, 936-941. DOI: 10.4028/www.scientific.net/KEM.602-603.936.

3. Wodecka-Duś, B., \& Czekaj, D. (2011). Synthesis of $0.7 \mathrm{BiFeO}_{3}-0.3 \mathrm{BaTiO}_{3}$ ceramics: thermal, structural, and AC impedance studies. Arch. Metal. Mater., 56(4), 1127-1136. DOI: 10.2478/v10172-011-0126-5.

4. Kowal, K., Jartych, E., Guzdek, P., Stoch, P., Wodecka-Duś, B., Lisińska-Czekaj, A., \& Czekaj, D. (2013). X-ray diffraction, Mössbauer spectroscopy and magnetoelectric effect studies of $\left(\mathrm{BiFeO}_{3}\right)_{x}-\left(\left(\mathrm{BaTiO}_{3}\right)_{1-x}\right.$ solid solutions. Nukleonika, 58(1), 57-61.

5. Chandarak, S., Unruan, M., Sareein, T., Ngamjarurojana, A., Maensiri, S., Laoratanakul, P., Ananta, S., \& Yimnirun, R. (2009). Fabrication and characterization of (1-x) $\mathrm{BiFeO}_{3}-\mathrm{xBaTiO}_{3}$ ceramics prepared by a solid state reaction method. J. Magn., 14(3), 120-123. DOI: 10.4283/JMAG.2009.14.3.120.

6. Ismailzade, I. H., Ismailov, R. M., Alekberov, A. I., \& Salaev, F. M. (1981). Investigation of the magnetoelectric (ME) H effect in solid solutions of the systems $\mathrm{BiFeO}_{3}-\mathrm{BaTiO}_{3}$ and $\mathrm{BiFeO}_{3}-\mathrm{PbTiO}_{3}$. Phys. Status Solidi A-Appl. Mat., 68, K81-K85. DOI: 10.1002/ pssa.2210680160.

7. Park, T. J., Papaefthymiou, G. D., Viescas, A. J., Lee, Y., Zhou, H., \& Wong, S. S. (2010). Composition-dependent magnetic properties of $\mathrm{BiFeO}_{3}-\mathrm{BaTiO}_{3}$ solid solution nanostructures. Phys. Rev. B, 82, 024431-124431-10. DOI: 10.1103/PhysRevV.82.024431.

8. MacKenzie, K. J. D., Dougherty, T., \& Barrell, J. (2008). The electronic properties of complex oxides of bismuth with the mullite structure. J. Eur. Ceram. Soc., 28, 499-504. DOI: 10.1016/j.jeurceramsoc.2007.03.012.

9. Mahesh Kumar, M., Srinivas, A., Kumar, G. S., \& Suryanarayana, S. V. (1999). Investigation of the magnetoelectric effect in $\mathrm{BiFeO}_{3}-\mathrm{BaTiO}_{3}$ solid solutions. J. Phys.-Condens. Matter, 11, 8131-8139. DOI: 10.1088/0953-8984/11/41/315.

10. Kim, J. S., Cheon, C. I., Lee, C. H., \& Jang, P. W. (2004). Weak ferromagnetism in the ferroelectric $\mathrm{BiFeO}_{3}-\mathrm{ReFeO}_{3}-\mathrm{BaTiO}_{3}$ solid solutions $(\mathrm{Re}=\mathrm{Dy}, \mathrm{La})$. J. Appl. Phys., 96, 468-474. DOI: 10.1063/1.1755430. 